\title{
AN ASSESSMENT OF THE STEADY-STATE CARBON MONOXIDE METHOD OF ESTIMATING PULMONARY DIFFUSING CAPACITY
}

\author{
BY \\ J. MacNAMARA, F. J. PRIME, AND J. D. SINCLAIR \\ From the Department of Physiology, Institute of Diseases of the Chest, Brompton Hospital, London
}

(RECEIVED FOR PUBLICATION SEPTEMBER 22, 1958)

For the past three years we have been using Bates's steady-state carbon monoxide technique for estimating the efficiency of gas transfer through the lungs as a routine laboratory procedure (Bates, Boucot, and Dormer, 1955). This paper reports certain formal investigations carried out to assess the usefulness and accuracy of the method and to help us to choose which of three ways in which the results can be expressed would be the most informative. These were the apparent diffusing capacity $\left(D_{\nu}\right)$, percentage uptake of carbon monoxide, and what we have called the "conductance" of the lungs $\left(C_{L}\right)$, a term we took from Dornhorst (1952). Numerous investigators have used the first two indices (see Bates and others, 1955 ; Forster, 1957), but the last has not to our knowledge been used before. We chose a somewhat simplified version of Bates's method in preference to the single-breath technique described by Krogh and Krogh (1910), Forster, Cohn, Briscoe, Blakemore, and Riley (1955), and Ogilvie, Forster, Blakemore, and Morton (1957) because it demands a minimum of co-operation on the part of the patient, can be used as easily during exercise as during rest, and the calculations involved are very simple.

We selected for study a group of 21 normal subjects, 37 emphysematous patients, and 40 patients suffering from diffuse pulmonary disease such as interstitial fibrosis or sarcoidosis. The normal subjects ranged in age from 18 to 43 years; they showed no clinical or radiological evidence of disease, and other tests of pulmonary function failed to disclose any abnormality. Pulmonary emphysema was diagnosed on evidence of long-standing chronic bronchitis with undue breathlessness on effort; lung function tests showed restriction of ventilatory capacity, uneven alveolar ventilation, and in some instances chronic respiratory acidosis and low arterial blood oxygen saturation; all shades of clinical severity and radiological abnormality were seen in this group of patients. Diagnosis of diffuse interstitial disease was made mainly on the radiographic appearances of the lungs coupled with clinical findings. In some instances a pathological diagnosis was established by lung or lymph node biopsy. Lung volumes in these patients were below expected values whilst maximum breathing capacity was well maintained. These are typical findings in patients suffering from this sort of disease. The most important derangement of function shown by patients in this group is one which diminishes the rate at which oxygen can diffuse from alveolar gas into the alveolar capillary blood; it has been termed "alveolar-capillary block." This was not used as one of our diagnostic criteria in the present investigation.

\section{METHOD}

The apparatus we used was the bag-box arrangement (Fig. 1) described by Donald and Christie (1949). A device for sampling the last $60 \mathrm{ml}$. of each expiration, i.e., an end-tidal sampler, was fitted to the mouthpiece assembly as described by Rahn and Otis (1949). Openings were made in the inspiratory and expiratory sides of the breathing circuit through which gas samples could be withdrawn. Thick-walled rubber tubes lead from these openings and the end-tidal air sampler to three of five inlets of a glass manifold (9) fitted with glass taps; the two remaining taps of the manifold were connected to supplies of calibrating gas and to room air. The single outlet of the manifold was connected to a diaphragm pump (13) which impelled the gas sample, selected by opening the appropriate inlet tap, through a short drying tube filled with magnesium perchlorate, and thence to the sample tube of an infra-red gas analyser. The gas leaving the analyser was returned to the expiratory compartment of the breathing circuit. Volume 


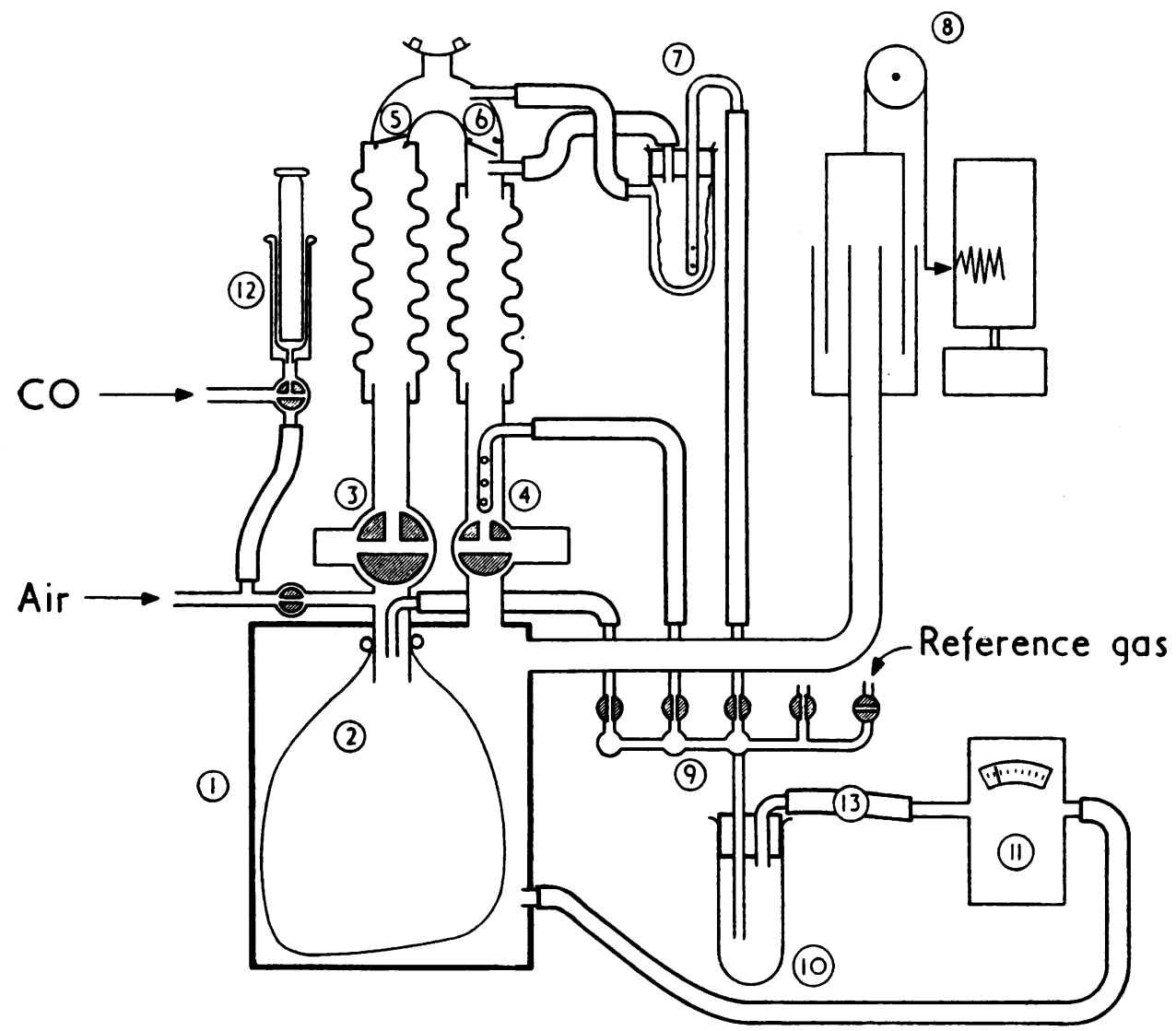

FIG. 1.-Diagram of the apparatus used for estimation of $D_{r}$ by the steady-state technique (slightly modified from Bates and others, 1955). (1) Rigid box enclosing (2) a rubber bag of $100 \mathrm{l}$. capacity; (3) and (4) wide-bore two-way stopcocks; (5) and (6) flaps of unidirectional valve; (7) Rahn-Otis end-tidal sampler; (8) recording spirometer; (9) glass manifold with five glass stopcocks; (10) drying tube containing magnesium perchlorate; (13) diaphragm pump impelling gas from the manifold and drying tube through the infra-red CO-analyser (11) into the box (1) outside the bag (2); (12) 20-ml. syringe for measuring the gas.

changes in the bag-box circuit were measured by means of a recording spirometer connected to the box. The volume of inspired and expired gas could be read from the spirometer record and the concentrations of $\mathrm{CO}$ in inspired, expired, and end-tidal gas could be measured successively with the infra-red analyser; from these results it was possible to calculate $(a)$ the percentage uptake of $\mathrm{CO},(b)$ the diffusing capacity of the lungs for $C O\left(D_{L}\right)$, and $(c)$ the conductance of the lungs $\left(C_{L}\right)$. These quantities are derived as follows:

Let $\mathrm{MV}_{\mathbf{I}}=$ volume of gas inspired per min. $(\mathrm{ml}$.$) .$

$, \mathrm{MV}_{\mathrm{E}}=,, \quad, \quad$, expired , , ,

$" F_{1}=$ fraction of $\mathrm{CO}$ in inspired gas

$" \mathrm{~F}_{\mathrm{Ex}}=, ",$, , expired ,"

$" F_{R t}=,,,,,$, , end-tidal ",

"BP = barometric pressure $\mathrm{mm} . \mathrm{Hg}$

" w.v.p. = water vapour pressure at room temperature
Volume uptake of $\mathrm{CO}=\mathrm{MV}_{\mathrm{I}} \times \mathrm{F}_{\mathrm{I}}-\mathrm{MV}_{\mathrm{Ex}} \times \mathrm{F}_{\mathrm{Ex}}$ $\mathrm{ml} . / \mathrm{min}$.

Partial pressure of $\mathrm{CO}$ in end-tidal gas $=\mathrm{F}_{\mathrm{Et}}(\mathrm{BP}-47) \mathrm{mm}$. $\mathrm{Hg}$

Partial pressure of $\mathrm{CO}$ in inspired gas

$$
=F_{I}(B P-\text { w.v.p. }) \mathrm{mm} \text {. Hg }
$$

Then the percentage extraction of $\mathrm{CO}$ is $\frac{(\mathrm{I})}{\mathrm{MV}_{\mathrm{I}} \times \mathrm{F}_{\mathrm{I}}} \times 100$ the $\mathrm{D}_{\mathrm{L}}=\frac{\text { (I) }}{\text { (II) }}$ and the $\mathrm{C}_{\mathrm{L}}=\frac{\text { (I) }}{\text { (III) }}$

In practice $M V_{I}$ and $M V_{E}$ are virtually equal, the difference being that between $\mathrm{O}_{2}$ uptake and $\mathrm{CO}_{2}$ excretion, a matter of $0-0.1 \mathrm{l}$. in 10-20 1 . No significant error is therefore introduced into the calculations if $M V_{I}$ and $M V_{E}$ are replaced by $M V$, the mean ventilation $(1 . / \mathrm{min}$.). This is estimated by drawing lines through the peaks and troughs of the spirogram and measuring the vertical distance between 
the lines; measured thus a value for tidal volume is obtained which is approximately the mean of inspired and expired volume. Multiplication of this figure by respiratory rate per minute gives the value for $\mathrm{MV}$.

\section{Procedure}

The bag in the apparatus is filled with air containing approximately $0.04 \%$ of carbon monoxide ; this gas is analysed for $\mathrm{CO}$ by sampling from the bag before the start of the test and at the end. In this way drift of the analyser is easily detected by a difference in the two readings; if these differ by more than $4 \%$ of the meter reading the whole test is repeated after resetting the analyser. The resting measurements are made with the patient seated; he is connected to the apparatus with a rubber mouthpiece and a nose-clip is fitted. Until he is comfortably settled he breathes room air. During this period mixed expired and end-tidal gas samples are passed through the infrared $\mathrm{CO}$ analyser; meter readings not exceeding $8 \%$ of full scale are usually recorded due to $\mathrm{CO}_{2}$ in the expired gas, which are subtracted from the corresponding $\mathrm{CO}$ concentrations recorded when the patient is breathing the air/CO mixture. After these readings have been made the kymograph of the spirometer is started and the two three-way taps, (3) and (4), are turned together so that the patient inhales the $\mathrm{CO}$ mixture from the bag of the apparatus and exhales into the box. Mixed expired gas is drawn through the analyser and breathing is continued until the concentration of $\mathrm{CO}$ registered has reached a constant level which is recorded; this usually takes between one and two minutes. The end-tidal gas is now sampled and the concentration of $\mathrm{CO}$ in this is recorded. Finally a sample of the inspired gas is analysed for $\mathrm{CO}$ concentration.

For tests made during exercise, the patients holds the mouthpiece assembly in his hands and carries out stepping exercise at any convenient rate, using a step $20 \mathrm{~cm}$. high; about 15 steps a minute are usually taken. The rest of the procedure is the same as that already described.

Certain comments on the efficiency of the apparatus are necessary. First, concerning the end-tidal sampler (7) ; this depends for its performance on pressures developed in the mouthpiece between the flaps ( 5 and 6) of the one-way valve. When breathing is normally deep these changes are sufficient to ensure vigorous expansion and collapse of the rubber bag in the sampler, but when breathing is very shallow (300 to $400 \mathrm{ml}$.) the movements of the bag are apt to be less than complete; in this case the bag never completely collapses and a smaller volume of end-tidal gas is taken from each breath; the effect of this is to prolong slightly the time required to wash out the gas analyser with end-expired gas. Should the sampler be emptied of gas by the sampling pump no risk is run of sampling gas delivered early in expiration because the thin walls of the bag close the holes in the tube leading from the bag to the pump. It is necessary to see that the glass parts of the sampler are dry before each test is carried out because the sampling bag may adhere to the wet glass too firmly for free movement. In normal subjects we were able to check the efficacy of the end-tidal gas sampler by comparing the $\mathrm{CO}_{2}$ concentration in the sample with the plateau concentration of $\mathrm{CO}_{2}$ recorded by an infrared $\mathrm{CO}_{2}$ analyser sampling expired gas close to the point where end-tidal gas was collected or from the rubber mouthpiece. We found that the peak values for $\mathrm{CO}_{2}$ concentration at these latter sites were the same as the concentration in the end-tidal samples; this we took as good evidence of reliable performance. The physiological significance of the end-tidal sample will be discussed later.

An important part of the apparatus is the infra-red $\mathrm{CO}$ analyser. This was subjected to tests for accuracy and stability in the course of other experiments on the dissociation of carboxyhaemoglobin (Pugh, 1956). We found that when great care was taken over the setting-up procedure the error in analysing a known mixture of $\mathrm{CO}$ was never more than $1 \%$ of full scale $(0.00 \%$ to $0.05 \%$ CO by volume) over the whole range and that in the course of 10 minutes instrumental drift could increase this error to $2 \%$ of full scale. Since the errors are systematic in amount and direction and the calculated volume of $\mathrm{CO}$ uptake depends mainly on the difference between inspired and expired $\mathrm{CO}$ concentration, the total error of estimation of $\mathrm{CO}$ uptake is very small. On the other hand the denominators of the ratios described above are absolute values and therefore the errors of estimating $\mathrm{CO}$ concentration affect the final value of the ratio in inverse proportion. The method we used for correcting for the presence of $\mathrm{CO}_{2}$ in the samples was justified by experiment with gas samples of known composition containing concentrations of $\mathrm{CO}_{2}$ up to $10 \%$; we found no increase in the error of estimating $\mathrm{CO}$ when this correction was applied, provided that the total deflection due to $\mathrm{CO}_{2}$ alone was not greater than $20 \%$ of full scale. When the detector unit of the analyser is in good working order, the meter readings obtained from expired gas are seldom as great as $4 \%$ of full scale; leakage of this unit is apt to occur during the course of six months or so which has the effect of increasing its sensitivity to $\mathrm{CO}_{2}$; we are accustomed to having the detector serviced when the meter reads $8 \%$ of full scale. As a result of other experimental work on this topic we consider that ideally end-tidal and mixed expired gas should be freed from $\mathrm{CO}_{2}$ by passage through soda-asbestos before reaching the $\mathrm{CO}$ meter; if this is done, the concentrations of $\mathrm{CO}_{2}$ in these gases must be separately determined in order that a correction may be made for the change of volume caused by the removal of $\mathrm{CO}_{2}$. Only thus can results of the highest accuracy be obtained, but in clinical practice this advantage is not worth the price in increased labour in the collection of data and calculation of results.

\section{RESULTS}

The accuracy of the steady-state method is mainly dependent upon the accuracy of the infra- 
red carbon monoxide gas analyser. Allowing an error of $2 \%$ of full scale in the readings of $\mathrm{CO}$ concentration, calculation shows that in one instance the possible value for $D_{L}$ lay between 14.3 and $15.4 \mathrm{ml} . / \mathrm{min} . / \mathrm{mm}$. Hg. In another example where $D_{L}$ was low the values lay between 4.5 and $6.1 \mathrm{ml} . / \mathrm{min} . / \mathrm{mm}$. Hg. Thus analytical errors are most important where the value of $D_{L}$ is low. The same applies to measurements of percentage uptake and $C_{L}$. Measurements of ventilation can be made reliably within $10 \%$ from a spirogram and more accurately than this if a gas meter is used. Since ventilation is used as a factor in the numerators of the ratios $D_{L}$ and $C_{L}$, a similar percentage error may occur in these. Thus, the errors in measurements of $D_{L}$ and $C_{L}$ may be as great as $40 \%$ when these values are low, but in general are better than this in the higher ranges.

The mean values for $D_{L}$ and percentage uptake obtained in normal subjects agree well with the findings of other workers (Filley, MacIntosh, and Wright, 1954; Bates and others, 1955). Likewise our results in emphysematous subjects are within the same range as those published by Bates, Knott, and Christie (1956). Marks, Cugell, Cadigan, and Gaensler (1957) gave results in patients with diffuse interstitial disease which fall within the range we have found in our group, but the average of their results is lower than ours; this may be because one of their diagnostic criteria was a low diffusing capacity whilst we selected our patients without reference to diffusing capacity. The range of values for percentage uptake of $\mathrm{CO}$ in our normal subjects is the same as Bates (1952) and Filley and others (1954) have found. Marks and others (1957) reported higher values because they based their calculations on estimates of alveolar ventilation. In our opinion this method of calculation largely vitiates the simplicity and directness of percentage uptake as an index of gas transfer.

Tables I and II and Fig. 2 show that there is some overlap between the findings in normal and abnormal subjects. It will be seen that measurements of conductance discriminate poorly between the normal and abnormal subjects whereas the same subjects were well separated by both the other measurements.

The reliability of the method was assessed by analysing the difference between the first and second of paired estimates carried out on each subject. The means and standard deviations of these differences are shown in Tables I and II ; they compare favourably with those of other workers. The most important concomitant of
TABLE I

MEAN VALUES AND STANDARD DEVIATIONS OF ESTIMATES OF DL, PERCENTAGE UPTAKE OF CO, AND $C_{L}$ IN A GROUP OF 21 NORMAL SUBJECTS AT REST AND DURING EXERCISE

\begin{tabular}{|c|c|c|}
\hline & $\begin{array}{l}\text { Seated at } \\
\text { Rest }\end{array}$ & $\begin{array}{l}\text { During Stepping } \\
\text { Exercise }\end{array}$ \\
\hline Mean $\mathrm{D}_{\mathrm{L}}$ (s.d.) $\mathrm{ml} . / \mathrm{min} . / \mathrm{mm} . \mathrm{Hg}$ & $23.3 \quad(4.93)$ & $32.5(5.63)$ \\
\hline $\begin{array}{llll}\Delta_{\mathrm{a}}^{\mathrm{b}} \text { (s.d.)* } & \ldots & \ldots & \ldots\end{array}$ & $-0.56(3.26)$ & $+4.88(5.49)$ \\
\hline Mean \% uptake CO (s.d.) & $51 \cdot 1 \quad(4 \cdot 66)$ & $42.9 \quad(5 \cdot 58)$ \\
\hline$\Delta_{\mathrm{a}}^{\mathrm{b}}$ (s.d.) $\quad \ldots \quad \ldots$ & $-0.64(3 \cdot 12)$ & $+0.78(2.73)$ \\
\hline Mean $C_{L}$ (s.d.) ml. $/ \mathrm{min} . / \mathrm{mm} . \mathrm{Hg}$ & $6.5 \quad(1.66)$ & $15.4(2.50)$ \\
\hline $\begin{array}{llll}\Delta_{\mathrm{a}}^{\mathrm{b}} \text { (s.d.) } & \cdots & \cdots & \ldots\end{array}$ & $+0.31(1.06)$ & $+2 \cdot 2 \quad(1 \cdot 86)$ \\
\hline
\end{tabular}

* The mean difference $\left(\Delta_{a}^{b}\right)$ between the first (a) and second (b) of paired estimates is also shown. The subjects ranged in age from 18 to 43 years about a mean of 31 years.

\section{TABLE II}

MEAN VALUES AND STANDARD DEVIATIONS OF $D_{L}$, PERCENTAGE UPTAKE OF CO, AND $C_{L}$ IN 37 EMPHYSEMATOUS AND 43 PATIENTS SÜFERING FROM DIFFUSE INTERSTITIAL DISEASE ("PULMONARY FIBROSIS")

\begin{tabular}{|c|c|c|c|}
\hline & & $\begin{array}{c}\text { Seated } \\
\text { at } \\
\text { Rest }\end{array}$ & $\begin{array}{l}\text { During } \\
\text { Stepping } \\
\text { Exercise }\end{array}$ \\
\hline $\begin{array}{l}\text { Emphy- } \\
\text { sema } \\
\text { in } 37 \\
\text { patients }\end{array}$ & 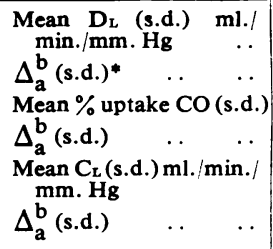 & $\begin{array}{c}12.2(5.87) \\
-0.02(1.45) \\
31.9(5.59) \\
+0.24(3.16) \\
5.5(1.65) \\
+0.03(1.26)\end{array}$ & $\begin{array}{c}22.7(11 \cdot 12) \\
-^{\dagger} \\
28.0(5.37) \\
-_{\dagger}^{\dagger} \\
11.39(3.51) \\
-^{\dagger}\end{array}$ \\
\hline $\begin{array}{l}\text { " Diffuse } \\
\text { fibrosis " } \\
\text { in } 43 \\
\text { patients }\end{array}$ & 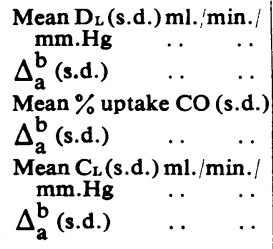 & $\begin{array}{r}10.4(4.21) \\
+0.34(1.57) \\
32.4(10.14) \\
+0.56(2.93) \\
\\
5.0(1.03) \\
-0.06(0.99)\end{array}$ & $\begin{array}{c}17.2(6.03) \\
+0.11(3.87) \\
28.6(2.87) \\
-0.62(2.38) \\
\\
10.0(2.98) \\
-0.88(2.63)\end{array}$ \\
\hline
\end{tabular}

* Mean and standard deviations of the differences between the first and second of the paired observations are also shown $\left(\Delta_{a}^{b}\right)$

$\dagger$ Insufficient duplicate estimates obtained for analysis in this group.

TABLE III

MEAN VALUES AND STANDARD DEVIATIONS OF ESTIMATES OF $D_{L}$, PERCENTAGE UPTAKE OF CO, AND $C_{L}$ IN THREE SUBJECTS REPEATEDLY TESTED OVER 10 MONTHS AND MEASUREMENTS OF MINUTE VOLUME DURING THE

\begin{tabular}{|c|c|c|c|c|c|c|}
\hline \multicolumn{7}{|c|}{ TEST } \\
\hline & Age & $\begin{array}{l}\text { No. of } \\
\text { Esti- } \\
\text { mates }\end{array}$ & $\underset{\text { (ml./ }}{\mathrm{D}_{\mathbf{l}}}$ & $\begin{array}{l}\text { Uptake } \\
\text { of } \\
\text { CO }\end{array}$ & 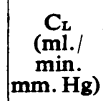 & $\begin{array}{c}\text { M.V. } \\
(1 . / \mathrm{min} .)\end{array}$ \\
\hline $\begin{array}{ll}\text { J. MacN. } & \text { M.d. } \\
\text { s.d. } & \cdots \\
\text { F.J.P. } & \cdots \\
\text { J.D.d. } & \cdots \\
\text { s.d. } & \cdots\end{array}$ & 43 & $\frac{25}{11}$ & $\begin{array}{c}21.8 \\
2.06 \\
16.2 \\
2.55 \\
21.8 \\
2.23\end{array}$ & $\begin{array}{c}50.7 \\
1.51 \\
48.0 \\
2.10 \\
54 \cdot 2 \\
1.01\end{array}$ & $\begin{array}{l}5.7 \\
0.49 \\
5.5 \\
0.73 \\
5.7 \\
0.57\end{array}$ & $\begin{array}{l}8 \cdot 7 \\
0.08 \\
8.8 \\
2 \cdot 55 \\
7 \cdot 5 \\
1 \cdot 17\end{array}$ \\
\hline
\end{tabular}


Apparent Diffusing Capacity (ml./min./mm. $\mathrm{Hg}$ )

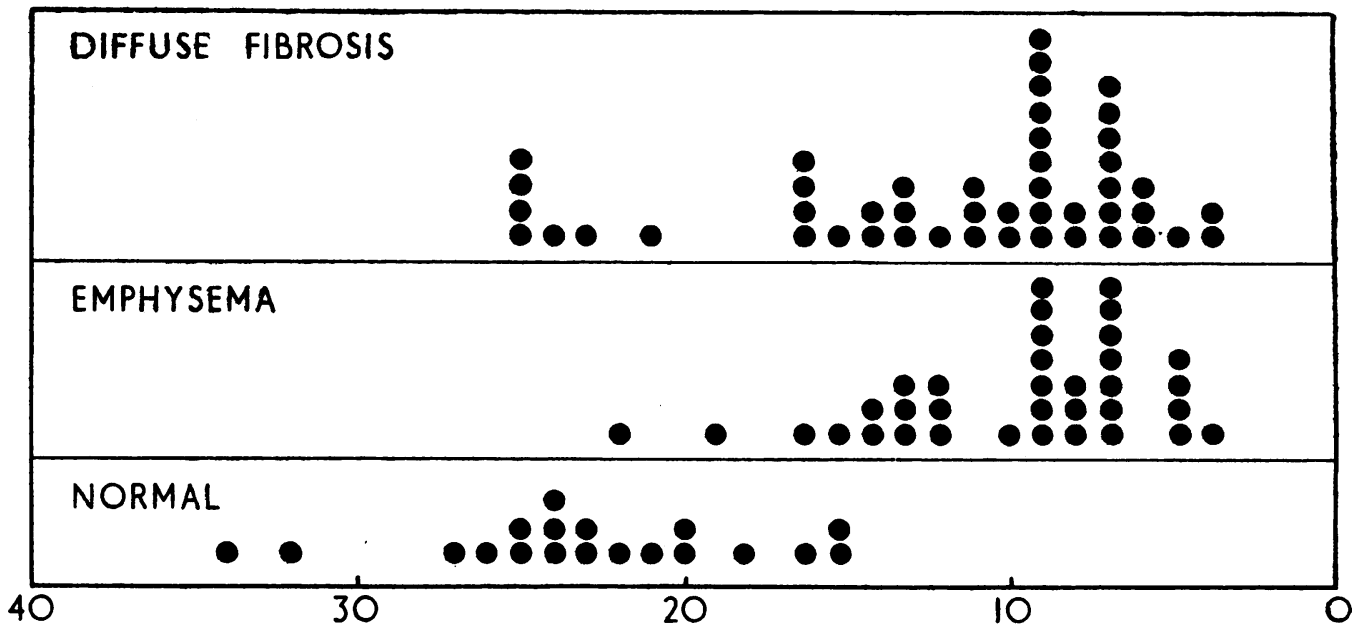

Percentage Extraction

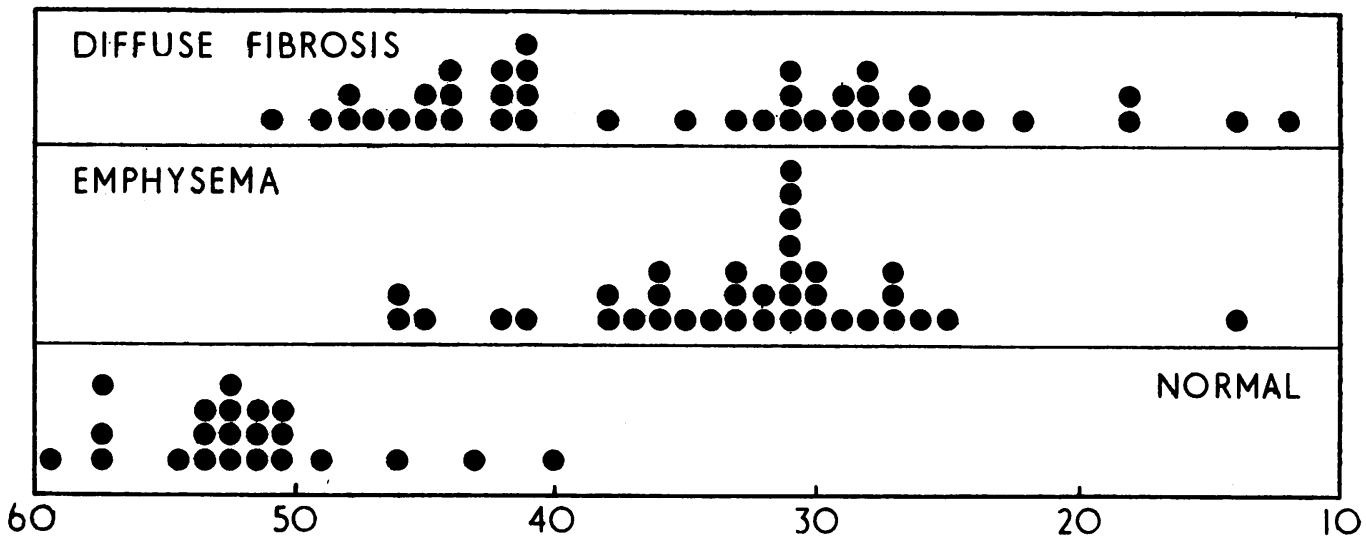

Conductance (ml./min./mm. $\mathrm{Hg})$

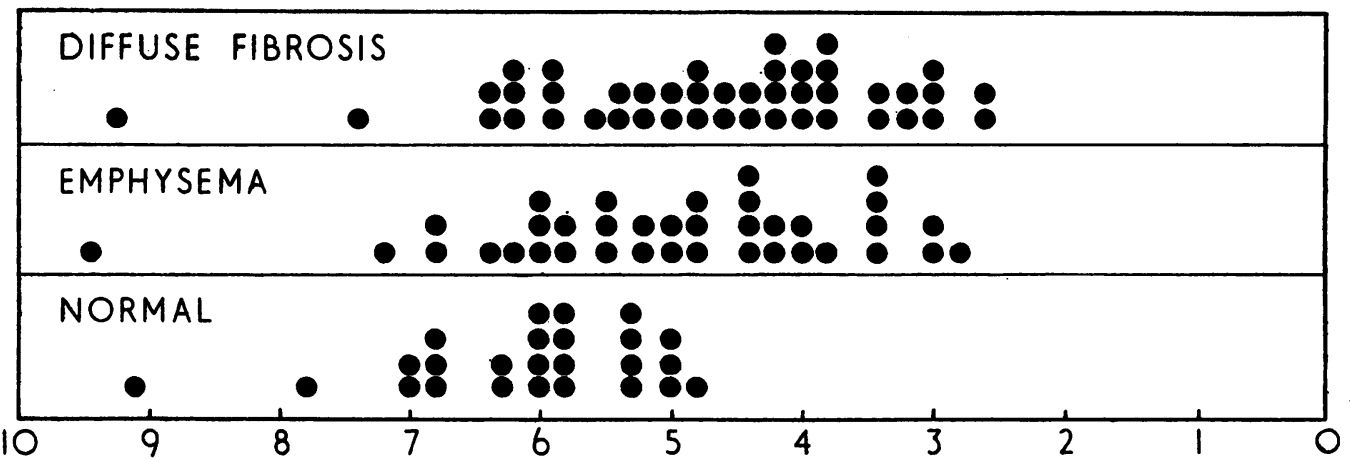

FIG. 2.-Spot diagram showing the distribution of estimates of $\mathrm{D}_{\mathbf{L}}$, percentage extraction of $\mathrm{CO}$, and $\mathrm{C}_{\mathrm{L}}$ in two groups of patients and a group of normal subjects. The term " diffuse fibrosis" includes diffuse pulmonary lesions which may lead ultimately to fibrosis, e.g., sarcoidosis, as well as established fibrosis. Note that $C_{k}$ in many instances does not fall in the presence of pulmonary disease. 
large differences between the individual estimates of a pair was found to be a change in ventilation. This affected measurements of $D_{L}$ and $C_{L}$ most. Thus $D_{L}$ increased by an average of $0.77 \mathrm{ml}$./ $\mathrm{min} . / \mathrm{mm}$. $\mathrm{Hg}$ in subjects whose ventilation increased by less than $1 \mathrm{l} / \mathrm{min}$. and by 2.0 $\mathrm{ml} . / \mathrm{min} . / \mathrm{mm} . \mathrm{Hg}$ where the change in ventilation was $3.51 . / \mathrm{min}$. We have investigated these changes more fully and our findings will be reported elsewhere (MacNamara, Prime, and Sinclair, 1959). Changes of ventilation hardly affect percentage uptake unless they are large, when this value falls (Gilson and Hugh-Jones, 1955).

Table III shows the degree of scatter observed in the three indices measured in three normal subjects over a period of about six months. They agree with a similar set of data given in respect of $D_{L}$ only by Bates and others (1955) in one subject and confirm the general reliability of the figures derived from the steady-state method.

The increase in rate of gas transfer brought about by exercise was determined in all the patients ; duplication was not feasible in some of the severely emphysematous. Exercise diminishes percentage uptake and will not be considered in detail here; we agree with Bates (1952) that an index of gas transfer which falls on exercise in the face of an increased capacity for transferring gas needlessly hampers interpretation. In normal subjects there was considerable variation in the magnitude of the increase in $D_{L}$; the smallest increase was $40 \%$ and the largest $100 \%$. Filley and others (1954) suggest that $D_{L}$ reaches a maximum value on exercise when oxygen consumption is of the order of $1,200 \mathrm{ml}$./min. which is more than twice that achieved during the stepping exercise at 15 steps a minute which our subjects carried out and is beyond the capacity of most of the patients we see. For this reason no attempt was made to determine the maximum value for either $D_{L}$ or $C_{L}$ in this investigation. The increase in $D_{L}$ and $C_{L}$ which occurred on exercise in both groups of patients showed considerable individual variation. There was no relation between the magnitude of $D_{L}$ and $C_{L}$ at rest and that reached after exercise in the normals or the emphysematous patients, but in those with fibrosis there is an apparent correlation between the two values (see Fig. 3).

\section{Discussion}

In presenting this method and our results it is our aim to recommend its use as a laboratory procedure giving valuable data to the clinician. Interpretation of the results depends upon some
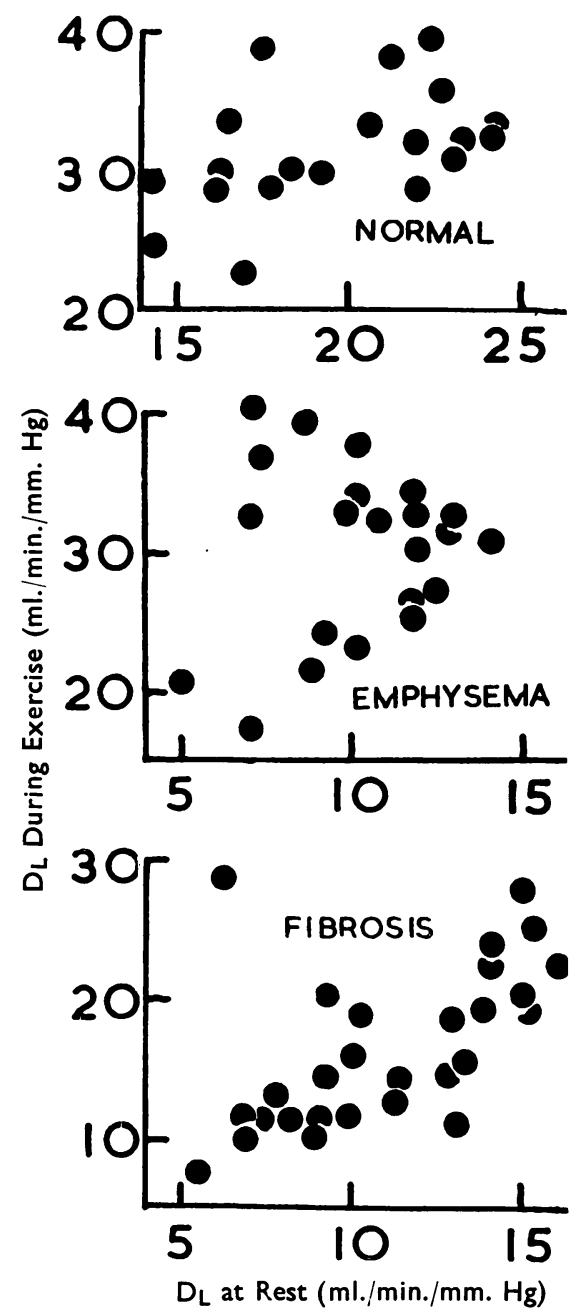

FIG. 3.-Diagram showing the effect of exercise on estimates of $D_{L}$ in a group of normal subjects and two groups of patients.

important points in the theory of gas transfer in the lungs.

Consider first the rate at which carbon monoxide passes through the pulmonary alveolar membranes. This is directly proportional to the difference in partial pressure of $\mathrm{CO}$ on either side of the membrane and to the area of the membrane ; it is inversely proportional to the thickness of the membrane. Thus :

$$
\begin{aligned}
& \frac{\mathrm{V}}{\mathrm{t}}=\frac{\text { K.A. } \times\left(\mathbf{P}_{\mathrm{A} . \mathrm{Co}}-\mathbf{P}_{\mathrm{C} . \mathrm{Co}}\right)}{\mathrm{T}} \\
& \text { where } \mathrm{V} \boldsymbol{I}=\text { the vclume of } \mathrm{CO} \text { absorbed (ml.) } \\
& t=\text { time required to absorb } \mathrm{Vml} \text {. of } \mathrm{CO} \\
& \text { (min.) } \\
& \mathrm{A}=\text { area of alveolar surface }\left(\mathrm{cm} .{ }^{2}\right) \\
& \mathrm{T}=\text { thickness of alveolar membranes } \\
& \text { (cm.) }
\end{aligned}
$$


$\mathbf{P}_{\mathbf{A} . \mathrm{Co}}$ and $\mathrm{P}_{\mathrm{C} . \mathrm{C} O \mathrm{O}}=$ partial pressures of $\mathrm{CO}$ in the alveolar gas and capillary blood respectively $(\mathrm{mm} . \mathrm{Hg})$

$\mathrm{K}=$ difiusion constant of the alveolar membrane

Rearranging this equation:

$$
\frac{\mathrm{V}}{\left(\mathrm{P}_{\mathrm{A} . \mathrm{Co}}-\mathrm{P}_{\mathrm{C} . \mathrm{co}}\right) \mathrm{t}}=\mathrm{K} \cdot \frac{\mathrm{A}}{\mathrm{T}}
$$

The left-hand side of equation (2) is equivalent to $D_{t}$, being expressed in terms of $C O$ absorption in $\mathrm{ml} . / \mathrm{min}$. divided by the $\mathrm{CO}$ pressure gradient in $\mathrm{mm}$. $\mathrm{Hg}$. Equation (2) shows that $\mathrm{D}_{\mathrm{L}}$ contains the ratio of the area of the alveolar membrane to its thickness; since there is no method of determining these independently, it follows that changes in $D_{L}$ can be due to changes in either of them. Thus the diagnosis of alveolar-capillary block due to thickening of alveolar walls cannot be made on the strength of a low value for $D_{k}$ alone; support is required from clinical and pathological sources, as well as from other function tests, to exclude emphysema which diminishes the effective area of the alveolar membrane. It used to be thought that the thickness of the membrane $T$ was substantially that of the alveolar and capillary walls together with any fluid or cellular exudate they might contain. It was assumed that, once the carbon monoxide penetrated this barrier, combination with the corpuscular haemoglobin was so rapid that no pressure of $\mathrm{CO}$ could be built up in the blood plasma and so reduce the pressure head ( $\left.\mathbf{P}_{\text {A.CO }}-\mathbf{P}_{\mathbf{C} . \mathbf{C O}}\right)$ which drives the gas into the blood. This assumption was criticized by Forbes, Sargent, and Roughton (1945); subsequent work by Roughton and his group (Gibson, Kreuzer, Meda, and Roughton, 1955 ; Forster, Roughton, Cander, Briscoe, and Kreuzer, 1957 ; Roughton and Forster, 1957) has demonstrated conclusively that significant pressure gradients are formed within the blood itself. It follows that for the purposes of this test the alveolar membrane includes a layer of blood plasma and the stroma of the red blood corpuscles, since it is only when the carbon monoxide is bound to the haemoglobin that its partial pressure can be neglected. Refined methods employed by Roughton and Forster and their colleagues have shown that this blood component in normal subjects contributes about half of the total resistance to gas transfer from alveolus to the intracellular haemoglobin. It is not yet possible to apply these methods to investigate abnormal subjects.

The important assumption that the mean partial pressure of $\mathrm{CO}$ in the alveoli $\left(\mathbf{P}_{\mathrm{A} . \mathrm{CO}}\right)$ can be measured in the expired gas is only approximately true even in normal subjects; in the diseased, the assumption is quite unjustified. There is no way of selecting a part of a single expiration having a composition which is a mean of that in all the pulmonary alveoli in an emphysematous lung. It is for this reason that we have calculated values for percentage uptake and $C_{L}$ which are based on unambiguous experimental findings. The difficulty in obtaining a suitable alveolar sample arises from lack of uniformity in the distribution of ventilation and perfusion which is extreme in patients with advanced emphysema. The use of end-tidal gas samples for estimating $P_{A . C o}$ can be justified only by the usefulness of the results which can be obtained in this way. The results shown in Fig. 2 and the tables amply support this admittedly unsatisfactory solution of the difficulty; further support is provided by the findings of Bates and others (1956) which show that very low values for $D_{L}$ in emphysematous subjects are associated with a bad prognosis.

Filley and others (1954) circumvented the endtidal sample by calculating the value of $P_{A . C o}$; they measured the arterial blood $\mathrm{pCO}_{2}$, the respiratory quotient, and the composition of inspired gas, substituting these results in an alveolar air equation similar to the one used by Riley for calculating mean alveolar oxygen concentration (Riley, Cournand, and Donald, 1951). This stratagem has the great advantage that the arterial blood gases are measured as part of the procedure, thus enlarging the scope of the investigation considerably; it complicates a simple technique to an undesirable degree, however, and in our view robs the steady-state $\mathrm{CO}$ technique of any advantage it has over Riley's method of estimating $D_{L}$.

Our measurements of percentage uptake are interesting because they distinguish the normal from the abnormal subjects as efficiently as $D_{L}$. There are, however, some patients in whom a normal value for $D_{L}$ is associated with a low percentage uptake. In one such case the patient hyperventilated at $201 . / \mathrm{min}$. during the test; $D_{L}$ was $23 \mathrm{ml} . / \mathrm{min} . / \mathrm{mm}$. $\mathbf{H g}$ whilst percentage uptake was only $36 \%$; we consider that the hyperventilation led to a misleadingly high value for $D_{L}$ and low value for percentage uptake and that had ventilation been only $10 \mathrm{l} / \mathrm{min}$. the results would have been of the order of $15 \mathrm{ml} . / \mathrm{min} . / \mathrm{mm}$. $\mathrm{Hg}$ and $50 \%$, i.e., about normal. This kind of difficulty in interpretation is unfortunately not infrequent in routine laboratory practice; we therefore strongly recommend that the ventilation 
Fig. 4.-Diagram demonstrating the independence of diffusing capacity and maximum voluntary ventilation in patients with emphysema and pulmonary fibrosis.

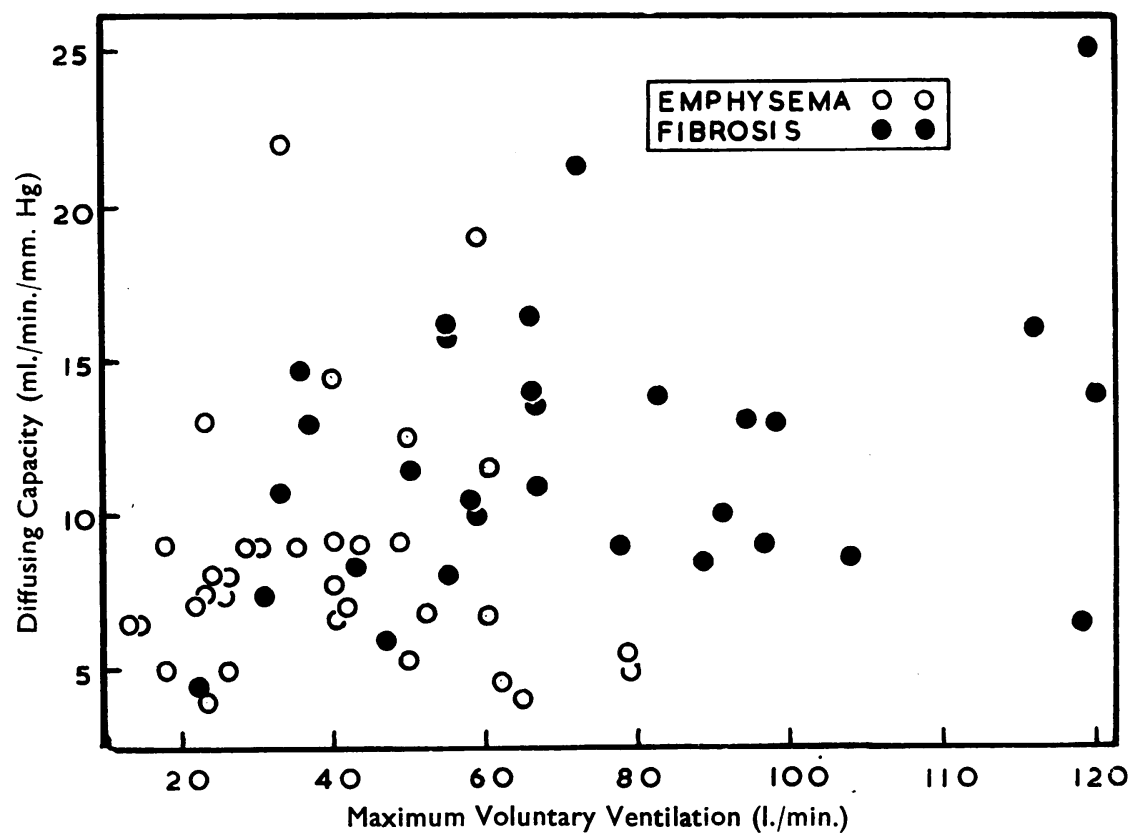

during the test be stated in reporting estimates of $D_{\text {L. }}$.

Conductance does not apparently distinguish normal subjects from patients as sharply as either $D_{L}$ or percentage uptake. However, it provides an accurate measure of gas transfer from room air to pulmonary capillary blood at the time of the test and thus is an index of the efficiency of the whole conducting pathway; like $D_{L}$ and percentage uptake it cannot distinguish the effects of unequal ventilation/perfusion ratios within the lungs from those of pure alveolar-capillary block and may frequently give results within the normal range in patients who are moderately disabled by pulmonary disease. Thus, although in a given patient $D_{L}$ may be low, $C_{L}$ may be within normal limits, indicating that a lesion affecting the diffusing capacity is compensated by an increase in alveolar ventilation, which raises the mean alveolar partial pressure of $\mathrm{CO}$, permitting a high rate of gas transfer. Hyperventilation and exercise increase conductance as they do diffusing capacity.

The increase in $D_{L}$ and $C_{L}$ which is observed invariably during exercise in normal subjects, and to a less extent and not invariably in patients, is due in part to an increase in ventilation/perfusion ratios of large numbers of the alveoli and in part also to an increase in the area of the diffusing surface. In normal subjects a threefold increase in $\mathrm{D}_{\mathrm{L}}$ is not uncommon on exercise ; in patients the increase may be trifling or absent (see Fig. 3). It is not possible to state that a maximum value can be reached in exercise by normal subjects by increasing the rate of work; we find that this is true in some but not in very athletic subjects. We always investigate the effect of exercise in patients because we consider that the extent of the increase in $D_{L}$ is a valuable indication of the presence of a physiological reserve. For the purpose of the test an amount of exercise easily tolerated by the patient is used rather than an amount fixed for all patients. In stepping exercise, most patients will take 15-18 steps a minute if allowed to choose for themselves; this is sufficient to induce a rise in $D_{L}$ if any change is possible. In those patients who are unable to exercise, use is made of the finding that voluntary hyperventilation at about twice their normal rate can be used instead to provide an increase in $D_{L}$. This effect is discussed at length elsewhere (MacNamara and others, 1959).

In spite of the theoretical and practical difficulties outlined above, variations in the rate of uptake of carbon monoxide are mainly determined by changes in the alveolar surface. Therefore, in the absence of grossly uneven alveolar ventilation, this test provides an estimate of diffusing capacity of the pulmonary alveoli no matter how the results are expressed. It is interesting to note that there is no apparent relation between $D_{L}$ and maximum breathing capacity (see Fig. 4); this is 


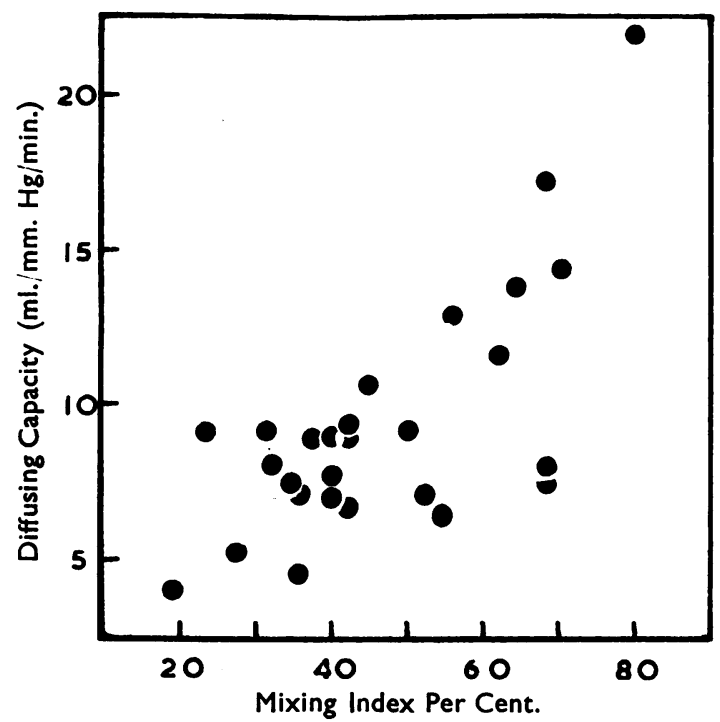

FIG. 5.-Diagram showing the association between uneven alveolar ventilation, as measured by the mixing efficiency, with low values of $D_{L}$ in emphysematous patients.

taken as evidence of specificity of the test. On the other hand, the important part played by uneven alveolar ventilation in determining the value of $D_{L}$ is emphasized by the results obtained in emphysematous patients (Fig. 5).

In its application to clinical problems the figure for $D_{L}$ occasionally contributes to diagnosis and is often helpful in assessing severity and prognosis in disease. Similarly it is useful for following the course of a disease and the effect of treatment.

The following are examples of diagnostic uses of the test:

A woman clerk, aged 43 years, had an illness suggestive of a systemic collagen disease; she complained of frequent coughs and colds, had a normal exercise tolerance and a normal chest radiograph, though a previous film had shown widespread shadows. Lung function tests showed a slightly reduced total lung volume, normal forced expiration at $1.0 \mathrm{sec} .\left(\frac{\text { FEV }_{1.0}}{\mathrm{FVC}}=\frac{1,450}{1,700}=85 \%\right)$, and normal mixing of inspired helium. The $\mathrm{D}_{\mathrm{L}}$ was 7.6 $\mathrm{ml} . / \mathrm{min} . / \mathrm{mm}$. $\mathrm{Hg}$ at rest and $12.5 \mathrm{ml} . / \mathrm{min} . / \mathrm{mm}$. $\mathrm{Hg}$ on exercise. It was concluded that in spite of the absence of symptoms, and clinical signs in the chest, with a normal radiograph, moderately extensive interstitial lung disease was present. The specific nature of the disease must be deduced from other data.

A farmer, aged 30 years, once a champion athlete, complained of increasing breathlessness on effort. At various times he had had symptoms of an anxiety neurosis. Although his chest was normal on clinical examination, there was radiographic evidence of early emphysema. Lung function tests yielded results at low normal levels for a man of his age and physique (vital capacity 3,900 ; residual volume $44 \%$ of total lung volume ; maximum breathing capacity $90 \mathrm{l} . / \mathrm{min}$., mixing efficiency $70 \%$ (normally $70 \%$ or higher); arterial $\mathrm{O}_{2}$ saturation $98 \%$ ). $\mathrm{D}_{\mathrm{L}}$ during quiet ventilation at rest was $29.0 \mathrm{ml} . / \mathrm{min} . / \mathrm{mm}$. $\mathrm{Hg}$; this was taken as conclusive evidence against the presence of emphysema, thus supporting a diagnosis of anxiety state in this instance.

We have not used the test for long enough to give an accurate estimate of its value in assessing prognosis. Generally, however, like Bates and others (1956) we have found values around 5-6 $\mathrm{ml} . / \mathrm{min} . / \mathrm{mm}$. $\mathrm{Hg}$ to be associated with evidence of cardiac strain and have seen a number of patients with low $D_{L}$ develop frank cardiac failure in the few months after testing, even when at that time there was no evidence of cor pulmonale. We regard low values as of sinister significance, whether in emphysema or interstitial disease, whatever the current severity of signs or symptoms of disease.

The use of $D_{L}$ in following the progress of disease stems from the difficulty in clinical assessment of minor degrees of progress, especially in the interstitial lesions for which tests of forced expiration are not useful. We have measured $D_{1}$ repeatedly in a number of patients suffering from sarcoidosis and diffuse interstitial fibrosis during the administration of adrenocortical steroids and have frequently observed increases in $D_{L}$.

For example, a young married woman had worked for two years in a factory producing fluorescent lamps; her work entailed the handling of beryllium phosphor. In 1947, at the age of 23 years, she began to complain of shortness of breath on effort and a chest radiograph taken at this time showed miliary mottling of both lung fields. About this time she had erythema nodosum and small skin lesions on the hands which on section of a biopsy specimen showed typical sarcoid granulomata. Between 1950 and 1953 hypercalcaemia developed with calcium deposits in the conjunctivae, hands, and tympanic membranes together with impairment of renal function. Treatmen was started with cortisone and maintained for a year, during which time she became much less breathless; cortisone was then stopped. In January, 1957 breathlessness again became a prominent symptom and on this occasion $D_{\mathrm{L}}$ was measured and found to be only $8.9 \mathrm{ml} . / \mathrm{min} . / \mathrm{mm}$. Hg. Prednisolone was given in doses of $20 \mathrm{mg}$. a day; subjective improvement was prompt and $D_{L}$ rose in the following month to $11.0 \mathrm{ml}$. $/ \mathrm{min}$. $/ \mathrm{mm}$. Hg. Prednisolone has been maintained at $10 \mathrm{mg}$. a day since then, and, in February, $1958, D_{\mathrm{L}}$ had risen to $14 \mathrm{ml} . / \mathrm{min}$. $/ \mathrm{mm}$. $\mathrm{Hg}$; the patient no longer complains of breathlessness and is well in other respects. 
A brief account of this patient's case has been published by Citron (1955).

\section{Summary and CONClusions}

An account is given of the steady-state carbon monoxide technique of estimating the diffusing capacity $\left(D_{L}\right)$ of the lungs.

Results obtained using this method in normal subjects, in emphysematous patients, and in patients suffering from diffuse interstitial pulmonary disease are given. Values for diffusing capacity, percentage uptake of $\mathrm{CO}$, and conductance are compared, and it is shown that percentage uptake is as good an index of diffusing capacity as $D_{L}$ measured at rest. Conductance is of little use to the clinician. The uncertainty of the meaning of $D_{L}$ is emphasized in the discussion, but experience in its use has led to the conviction that it is not only diagnostically significant in some cases but may be helpful in prognosis.

We gratefully acknowledge the support of Dr. J. G. Scadding during the preparation of this work. As always, we are indebted to our colleagues who volunteered to act as normal controls and to our patients who unknowingly provided valuable data for analysis. Mr. P. K. Morgan, our chief technician during these experiments, designed and made the apparatus ; our work could not have been carried out without his help.

\section{REFERENCES}

Bates, D. V. (1952). Clin, Sci., 11, 21

- Boucot, N. G., and Dormer, A. E. (1955). J. Physiol. (Lond.), $129,237$.

Knott, J. M. S., and Christie, R. V. (1956). Quart. J. Med., 25, 137

Citron, K. M. (1955). Postgrad. med. J., 31, 516.

Donald, K. W., and Christie, R. V. (1949). Clin. Sci., 8, 21.

Dornhorst, A. C. (1952). St. Thomas's Rep., 2 Ser., 8, 69.

Filley, G. F. MacIntosh, D. J., and Wright, G. W.'(1954), J. clin. Invest., 33, 530.

Forbes, W. H., Sargent, F., and Roughton, F. J. W. (1945). Amer. J. Physiol., 143, 594 .

* Forster, R. E. (1957). Physiol. Rev., 37, 391.

- Cohn, J. E., Briscoe, W. A., Blakemore, W. S., and Riley, R. L. (1955). J. clin. Invest., 34, 1417.

Roughton, F. J. W., Cander, L., Briscoe, W. A., and Kreuzer, F. (1957). J. appl. Physiol., 11, 277.

Gibson, Q. H., Kreuzer, F., Meda, E., and Roughton, F. J. W. (1955). J.' Physiol. (Lond.), 129, 65.

Gilson, J. C., and Hugh-Jones, P. (1955). Spec. Rep. Ser. med. Res. Coun. (Lond.), No. 290

Krogh, A., and Krogh, M. (1910). Skand. Arch. Physiol., 23, 236.

MacNamara, J., Prime, F. J., and Sinclair, J. D. To be published.

Marks, A., Cugell, D. W., Cadigan, J. B., and Gaensler, E. A. (1957). Amer. J. Med., 22, 51 .

Ogilvie, C. M., Forster, R. E., Blakemore, W. S., and Morton, J. W. (1957). J. clin. Invest., 36, 1.

Pugh, G. E. (1956). Personal communication.

Rahn, H., and Otis, A. B. (1949). J. appl. Physiol., 1, 717.

Riley, R. L., Cournand, A., and Donald, K. W. (195i). Ibid., 4, 102.

Roughton, F. J. W., and Forster, R. E. (1957). Ibid., 11, 290.

* This paper contains a full discussion of all the known factors affocting gas transfer in the lungs. 